\title{
Co-Infections of Asymptomatic Malaria and Soil-Transmitted Helminths in School Children in Localities with Different Levels of Urbanization in the Mount Cameroon Region
}

\author{
Helen K. Kimbi ${ }^{1 *}$, Emmaculate Lum ${ }^{1}$, Samuel Wanji², Judith V. Mbuh'1, Judith L. Ndamukong-Nyanga', Ebanga E.J. Eyong ${ }^{1}$ and Joanne
} Lello $^{3}$

${ }^{1}$ Department of Plant and Animal Sciences, University of Buea, P.O. Box 63, Buea, Cameroon

${ }^{2}$ Department of Biochemistry and Microbiology, Faculty of Science, University of Buea, P.O. Box 63, Buea, Cameroon

${ }^{3}$ Cardiff University, School of Biosciences, Organism and Environment Group, Biomedical Building, Museum Avenue Cardiff, CF - $103 A X$, UK

\begin{abstract}
Malaria and Soil-Transmitted Helminths (STHs) do co-infect hosts and it has been speculated that urbanization alters the frequency and transmission dynamics of both infections. This study was aimed at finding out the influence of urbanization on the prevalence and intensity of co-infections of asymptomatic malaria and STHs in schoolchildren in the Mount Cameroon Region. A total of 235 and 208 children from Ekona (rural) and Great Soppo (urban) respectively aged 4-14 years were enrolled into a cross-sectional study. Blood films were Giemsa-stained for the determination of malaria parasite density and speciation. Capillary blood was spun for the determination of packed cell volume. Stool samples were examined by the Kato-Katz technique for the presence and intensity of STHs. The prevalences of malaria in Ekona and Great Soppo were, $92.34 \%$ and $82.70 \%$ respectively $\left(X^{2}=9.60, p=0.002\right)$. Malaria Geometric Mean Parasite Density (GMPD) in Ekona $(277 \pm 1988)$ was higher than that in Great Soppo (251 \pm 2400 parasites/ $\mu \mathrm{l})$. Prevalence of helminths was higher in Ekona $(43.82 \%)$ than Great Soppo $(11.54 \%)\left(X^{2}=60.12, p<0.001\right)$. Coinfections were higher in Ekona (41.70\%) than Great Soppo (10.58\%) $\left(X^{2}=45.83, p<0.001\right)$. Ascaris lumbricoides was the most prevalent helminth and also had the highest Geometric Mean Egg Density (GMED) in Ekona, followed by Trichuris trichiura and hookworm. A similar pattern was observed in Great Soppo except for T. trichiura which was the most prevalent helminth. Prevalences of anemia in Ekona and Great Soppo were $6.00 \%$ and $1.00 \%$ respectively. The highest prevalence of anemia, GMPD and GMED occurred in co-infected participants when compared to those infected only with malaria or STHs. The prevalence of the infeections decreased with increase in level of urbanization. Schoolbased control of these infections especially in rural areas will reduce their related morbidities.
\end{abstract}

Keywords: Co-infections; Asymptomatic malaria; Prevalence; Soiltransmitted helminths; Urbanization; Mount cameroon region

\section{Introduction}

Malaria and Soil-Transmitted Helminths (STHs) do co-infect hosts and it has been speculated that the level of urbanization greatly affects the frequency and transmission dynamics of both infections [1,2]. Both infections are parasitic diseases that cause high rates of morbidity and have similar geographical distributions in the tropics and sub-tropics [2] where climatic conditions, poverty and sanitary practices favour their high prevalence. Helminths are the most prevalent parasitic infections infecting more than a billion people worldwide [3] while malaria especially that caused by Plasmodium falciparum is the deadliest parasitic disease [4] and usually results in chronic debilitation, physical impairment of development and learning ability in children [5]. These represent a huge negative social impact in endemic areas. The most ubiquitous of STHs belong to a number of key genera -Ascaris, Trichuris and hookworms (Necator and Ancylostoma). Hookworms are the most pathogenic because of their propensity to feed on blood, resulting in anaemia. A. lumbricoides and T. trichiura have been associated with stunted growth and impaired cognitive functions in children [6]. These STHs with schistosomiasis are responsible for $40 \%$ worldwide morbidity from all trpoical infections, excluding malaria [7].

There have been conflicting reports about the relationship between STHs and malaria. Some authors have reported that STHs can either ameliorate [8] or exacerbate [9] malaria severity. As such helminth infected patients may be able to tolerate high malaria parasite densities without any serious clinical manifestations, although patients may become very anemic and act as a source of infection (gametocytes) to mosquitoes for further transmission $[4,8]$. There is also evidence that co-infection with multiple parasites may alter the immune responses [8].This is a major challenge for disease control because many of such asymptomatic malaria infections go undetected and untreated $[2,10]$.

In Cameroon the prevalences of both malaria and STHs are generally high and vary from one part of the country to another depending on the level of urbanization and environmental conditions especially those linked to sanitary practices [11]. Individuals in such areas are commonly co-infected with combinations of malaria parasites and STHs. Such co-infections do have more health implications and lead to clinical symptoms and pathology than for infection with single parasite species. Some parts of the Mount Cameroon region are undergoing rapid urbanization and there is paucity of the knowledge of parasitic infection risks in localities with different levels of urbanization. School-aged children have been reported to be at the highest risk of co-infections of both malaria and STHs and consequently anaemia

${ }^{*}$ Corresponding author: Dr. Helen K. Kimbi, Department of Plant and Animal Sciences, University of Buea, P.O. Box 63, Buea, Cameroon, Tel: +237 778366 03/9403 53 55; Fax: +237 333222 72; E-mail: hkimbi@yahoo.co.uk

Received February 11, 2012; Accepted March 12, 2012; Published March 19 2012

Citation: Kimbi HK, Lum E, Wanji S, Mbuh JV, Nyanga JLN, et al. (2012) CoInfections of Asymptomatic Malaria and Soil-Transmitted Helminths in School Children in Localities with Different Levels of Urbanization in the Mount Cameroon Region. J Bacteriol Parasitol 3:134. doi:10.4172/2155-9597.1000134

Copyright: @ $2012 \mathrm{Kimbi} \mathrm{HK}$, et al. This is an open-access article distributed unde the terms of the Creative Commons Attribution License, which permits unrestricted use, distribution, and reproduction in any medium, provided the original author and source are credited. 
Citation: Kimbi HK, Lum E, Wanji S, Mbuh JV, Nyanga JLN, et al. (2012) Co-Infections of Asymptomatic Malaria and Soil-Transmitted Helminths in School Children in Localities with Different Levels of Urbanization in the Mount Cameroon Region. J Bacteriol Parasitol 3:134. doi:10.4172/2155-9597.1000134

$[12,13]$. Although a number of studies have been carried out on malaria and STHs coinfections [13-15] in the Mount Cameroon region, none has specifically focused on the influence of urbanization on coinfections in school children. This study was therefore aimed at finding out if the level of urbanization influences the prevalence and intensity of co-infections of malaria and STHs in school children in the Mount Cameroon Region.

\section{Materials and Methods}

\section{Study areas}

This study was carried out in Government School (G.S.) in Ekona (rural area) and in the Cameroon Baptist Convention (C.B.C.) school in Great Soppo (urban area) between March and June 2008. Ekona is a rural community in the Mount Cameroon region and the inhabitants are mainly subsistence farmers, most of them poor and living in houses made up of planks with holes and crevices in the walls. Many houses usually have standing water (during the rainy season), farmlands and bushes around them. With the lack of latrines in some homes, defaecation on the soil is not uncommon. Great Soppo on the other hand is a relatively urbanized area in the Mount Cameroon region and the inhabitants generally have higher standards of living than the inhabitants of Ekona. Many of the inhabitants have steady jobs while some are traders. Over $70 \%$ of houses in Great Soppo are made up of cement bricks while the rest are made out of plank. Given the sloppy nature of the area, there is hardly any standing water found around houses in Great Soppo and the environment is generally cleaner and there are proper latrines in all homes. Both Ekona and Great Soppo have air temperatures ranging from $25-27^{\circ} \mathrm{C}$, relative humidity and annual rainfall of approximately $80 \%$ and $4000 \mathrm{~mm}$ respectively. The two areas have two distinct seasons, a cold rainy season that extends from mid-March to mid-November and a warm dry season that lasts for the rest of the year.

\section{Study design, subjects and ethics}

The study was cross-sectional and the prevalences and densities of STHs and malaria were estimated for both host populations from randomly selected school children aged 4-14 years old and encompassing both sexes.

Ethical and administrative clearances were obtained from the Ethics Comittee of the Delegations of Public Health and Basic Education respectively, South West Region, Cameroon. Visits were made to the schools to explain the objectives and potential benefits of the study (that children found positve for either infection would be treated) to the head teachers/teachers of the schools before giving out consent forms to the pupils. The purpose and methodology of the survey was explained and pre-arrangements with the teachers of each school were made on when to collect the samples. Informed consent forms were distributed in the various schools to the children to take to their parents/legal guardians asking for their consents before sample collection. Parents/legal guardians also had to indicate when the child was last dewormed or treated with antimalarials.

Those included in the study were those whose parents/legal guardians consented by signing the consent forms, children willing to participate in the study as children had to provide their informed assent before sample collection and children who had not received anti-malarials or anti-helmintics in the preceding one month. Out of 700 forms given out in Ekona, 241 parents agreed to their children participating in the study. Four children could not supply stool samples and; two others refused to comply with sample collection and were excluded from the study, giving a sample size of 235 pupils at that site.

In Great Soppo, 550 consent forms were given out and 208 parents/ legal guardians consented. All the children supplied the samples and were all included in the study.

\section{Collection and processing of blood samples}

Before sample collection, demographic data such as name, axillary temperature, age and sex of pupil were recorded in a structured questionnaire. Information on anti-malarial or antihelmintic use was recorded. After sterilizing the finger tip, blood was collected by pricking the finger, thick and thin blood films were prepared and Giemsastained. Blood was also collected into heparinized capillary tubes for the estimation of Packed Cell Volume (PCV). Blood films were observed under the X100 (oil immersion) objective of the microscope. Parasite densities were estimated by counting parasites (trophozoites and gametocytes) against 200 leukocytes in thick smears, assuming a White Cell Count (WBC) of 8000 leukocytes/ $\mu$ l blood [16]. If less than 10 parasites were found the reading was continued up to $500 \mathrm{WBC}$. The thin films were used for speciation using the identification tables of Cheesbrough [16]. Slides were read separately by two experienced microscopists independently and in the case of any discrepancies, slides were read again. Children positive for malaria were treated with a combination of malartin (artesunate) and amodiaquine in collaboration with the authorities of a nearby public health centre.

\section{Assessment of anaemia}

The blood-filled capillary tubes were centrifuged at 12,000g for 5 minutes and PCV values were read using a haematocrit reader. Anaemia was defined as haematocrit $<31 \%$ (1). PCV values $\geq 31 \%$ were considered as normal.Those diagnosed of anaemia were given iron sulphate.

\section{Collection and examination of stool samples}

During screening children were given universal bottles and instructed on how to do proper faeces collection. The Kato-Katz thick smear technique was used for the quantitative estimation of helminth eggs in stool [17]. Stool samples were processed within 12 hours after collection and micrscopically examined within 1 hour of preparation to avoid missing hookworm ova. Duplicate smears were prepared from each specimen. As a control measure, $10 \%$ of randomly selected smears were re-examined by a third experienced parasitologist who was blinded to the previous results. The intensity of infection of the species of worms was expressed as the number of eggs per gram (epg) of faeces [16]. All pupils positive for worm infection were treated with Mebendazole.

\section{Statistical analysis}

Data were analysed using the Microsoft Excel and SPSS for windows version 11.5 (Chicago, 1L, USA). Normally distributed qualitative parameters were assessed using the Pearson Chi Square test or Fisher's exact test.Variations between group means were compared using either Analysis of Variance (ANOVA) or Mann Whitney U test. The cut-off for assesssing statistical significance was set at $p \leq 0.05$. Parasite densities were $\log _{10}$ transformed before analysis.

\section{Results}

\section{Characteristics of the study population}

The overall prevalence of malaria was higher in the rural area, Eko- 
Citation: Kimbi HK, Lum E, Wanji S, Mbuh JV, Nyanga JLN, et al. (2012) Co-Infections of Asymptomatic Malaria and Soil-Transmitted Helminths in School Children in Localities with Different Levels of Urbanization in the Mount Cameroon Region. J Bacteriol Parasitol 3:134. doi:10.4172/2155-9597.1000134

Page 3 of 6

na $(92.34 \%, 217 / 235)$ than urban area, Great Soppo $(82.70 \%, 172 / 208)$ and the difference was significant $\left(\mathrm{X}^{2}=9.60\right.$, d.f. $\left.=1, p=0.002\right)$. The Geometric Mean Parasite Density (GMPD) in Ekona was higher (277 \pm 1988 parasites/ $\mu \mathrm{L})$ than that of Great Soppo $(251 \pm 2400$ parasites/ $\mu \mathrm{L})$ but the difference was not significant $(t=0.77, \mathrm{df}=1, p=0.442)$. Overall, helminth infections were more prevalent in Ekona $(43.83 \%$, $103 / 235)$ than in Great Soppo $(11.54 \%, 24 / 208)$ and the difference was significant $\left(\mathrm{X}^{2}=60.12, \mathrm{df}=1, p<0.001\right)$. In the rural area $41.70 \%$ $(98 / 235)$ of study participants were co-infected with malaria and any helminth species while in the urban area $10.58 \%(22 / 208)$ of participants were co-infected with malaria and any helminth species and the difference was highly significant $\left(\mathrm{X}^{2}=45.83, \mathrm{df}=1, p<0.001\right)$. Of the 235 pupils examined in the rural area, $6.00 \%(14 / 235)$ of them were anaemic while $1.00 \%(2 / 208)$ were anemic in the urban area.

Malaria parasite prevalence and density in relation to age of pupils in the rural and urban areas

The highest prevalence of malaria parasites in the rural area was

\begin{tabular}{|c|c|c|c|c|}
\hline \multirow[t]{2}{*}{ Age group } & \multicolumn{4}{|c|}{ Malaria prevalence } \\
\hline & Rural & Urban & Grand total & $\begin{array}{l}\text { Level of signifi- } \\
\text { cance between } \\
\text { localities }\end{array}$ \\
\hline$\leq 7$ & $71(100.00)$ & $50(78.13)$ & 121(89.63) & $x^{2}=17.33$ \\
\hline \multicolumn{5}{|l|}{$p<0.001$} \\
\hline $8-9$ & $66(95.65)$ & $40(83.33)$ & 106(90.60) & $x^{2}=5.04$ \\
\hline \multicolumn{5}{|l|}{$p=0.025$} \\
\hline $10-14$ & $80(83.33)$ & $82(86.32)$ & 162(84.81) & $x^{2}=0.05$ \\
\hline \multicolumn{5}{|l|}{$p=0.816$} \\
\hline Total & $217(92.34)$ & 172(82.70) & $389(87.81)$ & $x^{2}=9.60$ \\
\hline \multicolumn{5}{|l|}{$p=0.002$} \\
\hline $\begin{array}{l}\text { Level of significance } \\
\text { between age groups }\end{array}$ & $\begin{array}{c}X^{2}=5.84 p< \\
0.001\end{array}$ & $\begin{array}{l}X^{2}=1.44 p \\
=0.486\end{array}$ & & \\
\hline Age group & \multicolumn{2}{|c|}{$\begin{array}{c}\text { Malaria parasite } \\
\text { density(GMPD/Ml) }\end{array}$} & \multicolumn{2}{|c|}{ Range } \\
\hline$\leq 7$ & $490 \pm 2175$ & $176 \pm 1017$ & $40-5280$ & $U=925.00$ \\
\hline \multicolumn{5}{|l|}{$p<0.0001$} \\
\hline $8-9$ & $229 \pm 2510$ & $398 \pm 4477$ & $40-20000$ & $U=954.00$ \\
\hline \multicolumn{5}{|l|}{$p=0.022$} \\
\hline $10-14$ & $196 \pm 1069$ & $250 \pm 1167$ & $40-8000$ & $U=2955.00$ \\
\hline \multicolumn{5}{|l|}{$p=0.274$} \\
\hline Total & $277 \pm 1988$ & $251 \pm 2400$ & $40-20000$ & $U=17669.00$ \\
\hline \multicolumn{5}{|l|}{$p=0.407$} \\
\hline $\begin{array}{l}\text { Level of significance } \\
\text { between age groups }\end{array}$ & $\begin{array}{l}F=12.80 \\
p<0.001 \\
\mathrm{df}=2\end{array}$ & $\begin{array}{l}F=4.72 \\
p=0.01 \\
\mathrm{df}=2\end{array}$ & & \\
\hline
\end{tabular}

Table 1: The effect of age on malaria prevalence and parasite densities in rura and urban areas. recorded in the $\leq 7$ years age group $(100 \%, 71 / 71)$ while the lowest rate $(84.21 \%, 80 / 95)$ was recorded in the $10-14$ years age group and the difference between age groups was highly significant $\left(\mathrm{X}^{2}=15.84, \mathrm{df}=2, p\right.$ $<0.001$ ) (Table 1). In the urban area, the highest prevalence of malaria parasites $(85.42 \%, 82 / 96)$ occurred in the age group $10-14$ years while the lowest $(78.13 \%, 50 / 64)$ occurred in the age group $\leq 7$ years but the difference was not significant $\left(\mathrm{X}^{2}=1.44, \mathrm{df}=2, p=0.486\right)$ (Table 1 ).

The overall GMPD $( \pm$ SD) in the rural area $(277 \pm 1988$ parasites/ $\mu \mathrm{L})$ was similar to that of the urban area $(251 \pm 2400$ parasites $/ \mu \mathrm{L})$. The highest GMPD was found in children of age group $\leq 7$ years $(490 \pm$ 2175 parasites/ $\mu \mathrm{L}$ of blood) in the rural area while the lowest occurred in children aged 10-14 years $(196 \pm 1069 / \mu \mathrm{L}$ blood $)$ and the difference in GMPD was highly significant $(F=12.80, \mathrm{df}=2, p<0.001)$ (Table 1). In the urban area, the highest GMPD was found in children of age group 8 - 9 years $(398 \pm 4422$ parasites $/ \mu \mathrm{L})$ while the lowest was found in children aged $\leq 7$ years $(176 \pm 1017$ parasites $/ \mu \mathrm{L}$ blood $)$ and the difference was significant $(F=4.72, \mathrm{df}=2, p<0.008)$ (Table 1).

\section{Prevalence of helminth species and egg densities in rural and} urban areas

The overall prevalence of STHs in the rural area was $43.83 \%$ $(103 / 235)$ while in the urban, it was $11.54 \%(24 / 208)$ and the difference was highly significant $\left(\mathrm{X}^{2}=60.12, \mathrm{df}=1, p<0.001\right)$. In the rural area Ascaris lumbricoides was the most prevalent helminth (30.21\%, 71/235) followed by Trichuris trichiura $(25.96 \%, 61)$ and hookworm $(5.11 \%$, 12/235) (Table 2). Among the three helminth species, A. lumbricoides had the highest egg density per gram (Geometric Mean Egg Density, GMED) of stool $(3490 \pm 9430)$ in the rural area and it was significantly higher than that of the urban area $(793 \pm 2496: t=2.04, p<0.045)$. The GMED of T. trichiura $(135 \pm 367 \mathrm{epg})$ was significantly higher in the rural than urban area $(69 \pm 263 \mathrm{epg})(t=2.10, p<0.039)$ (Table 2).

\section{Prevalence of anemia with respect to age in the study popula- tion}

In the rural area the highest prevalence of anemia (2.60\%) was recorded in the age group $10-14$ years while the lowest (1.30\%) occurred in the age group $8-9$ years. In the urban area, the only age group that had anemic cases $(1.00 \%)$ was the $10-14$ years (Figure 1 ).

\section{Prevalence of helminth species/P. falciparum co-infection in rural and urban areas}

In the rural area, $A$. lumbricoides/P. falciparum co-infections were the most prevalent $(15.31 \%, 36 / 235)$ while co-infections of $P$. falciparum with hookworm $(0.85 \%, 2 / 235)$ and T. trichiuris/hookworm $(0.85 \%, 2 / 235)$ were the least prevalent (Table 3$)$, but the difference was insignificant $\left(\mathrm{X}^{2}=11.17, p=0.98\right)$. In the urban area T. trichiuris/P. fal

\begin{tabular}{|c|c|c|c|c|c|c|c|c|}
\hline \multirow{3}{*}{ Locality } & \multirow{3}{*}{$\mathbf{N}$} & \multirow{3}{*}{$\begin{array}{l}\text { Overall helminth } \\
\text { prevalence } n(\%)\end{array}$} & \multicolumn{6}{|c|}{ Helminth egg density (GMED) } \\
\hline & & & \multicolumn{2}{|c|}{ Ascaris } & \multicolumn{2}{|c|}{ Trichuris } & \multicolumn{2}{|c|}{ Hookworm } \\
\hline & & & $\mathbf{N}(\%)$ & epg \pm SD & n (\%) & epg \pm SD & n (\%) & epg \pm SD \\
\hline Rural & 235 & $103(43.83)$ & $71(30.21)$ & $3490 \pm 9430$ & $61(25.96)$ & $135 \pm 367$ & $12(5.11)$ & $62 \pm 286$ \\
\hline Urban & 208 & $24(11.54)$ & $6(2.88)$ & $793 \pm 2496$ & $16(7.69)$ & $69 \pm 263$ & $2(0.96)$ & $24 \pm 0.0$ \\
\hline Total & 443 & $127(28.67)$ & $77(17.38)$ & $890 \pm 3716$ & $77(17.38)$ & $117 \pm 349$ & $14(3.16)$ & $54 \pm 267$ \\
\hline $\begin{array}{l}\text { Significance of differ- } \\
\text { ence between localities }\end{array}$ & & $\begin{array}{l}x^{2}=60.12 \\
p<0.001\end{array}$ & & $\begin{aligned} t & =2.04 \\
p & =0.045\end{aligned}$ & & $\begin{array}{l}T=2.10 \\
P=0.039\end{array}$ & & $\begin{array}{l}U=6.00 \\
p=0.225\end{array}$ \\
\hline
\end{tabular}

$\mathrm{N}$ : Number of pupils examined

$\mathrm{n}$ : Number of pupils infected with helminths

epg: Eggs per gram of faeces

SD: Standard deviation

Table 2: Variation in the prevalence of helminths and egg densities in pupils in rural and urban areas. 
Citation: Kimbi HK, Lum E, Wanji S, Mbuh JV, Nyanga JLN, et al. (2012) Co-Infections of Asymptomatic Malaria and Soil-Transmitted Helminths in School Children in Localities with Different Levels of Urbanization in the Mount Cameroon Region. J Bacteriol Parasitol 3:134. doi:10.4172/2155-9597.1000134

Page 4 of 6

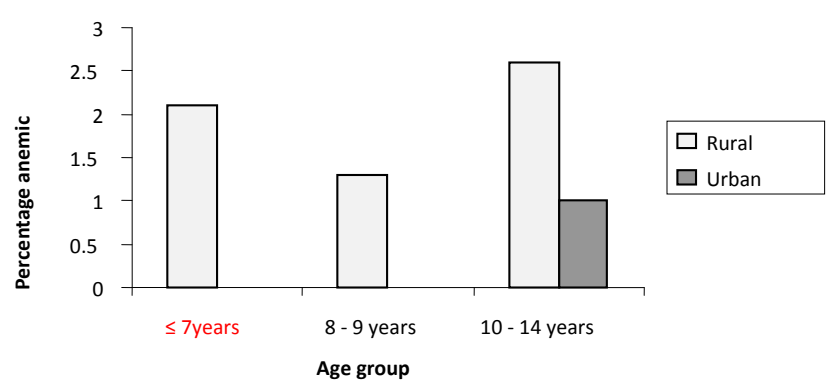

Figure 1: Prevalence of anemia by age of pupils in the study population for rural (light grey) and urban (dark grey) areas.

\begin{tabular}{|l|c|c|}
\hline \multirow{2}{*}{ Helminth species } & \multicolumn{2}{|c|}{ Plasmodium falciparum } \\
\cline { 2 - 3 } & Rural $\mathbf{n}(\%)$ & Urban $\mathbf{n}(\%)$ \\
\hline Ascaris & $36(15.31)$ & $6(2.88)$ \\
\hline Trichuris & $26(11.06)$ & $16(7.59)$ \\
\hline Hookworm & $02(0.85)$ & $0(0)$ \\
\hline Ascaris/Trichuris & $25(10.63)$ & $0(0)$ \\
\hline Ascaris/hookworm & $03(1.28)$ & $0(0)$ \\
\hline Trichuris/hookworm & $02(0.85)$ & $0(0)$ \\
\hline Ascaris/Tricuris/hookworm & $04(1.70)$ & $0(0)$ \\
\hline Total & $98(41.70)$ & $22(10.58)$ \\
\hline Significance of difference & $\mathrm{X} 2=11.17 ;$ & $\mathrm{X}^{2}=13.99 ;$ \\
& $\mathrm{p}=0.98$ & $\mathrm{p}=0.003$ \\
\hline
\end{tabular}

$\mathrm{n}$ : Number of helminth species/ P. falciparum co-infection

Table 3: Prevalence of helminth species/ P. falciparum co-infection in rural and urban areas.

\begin{tabular}{|l|c|c|c|c|}
\hline $\begin{array}{l}\text { Disease } \\
\text { Status }\end{array}$ & Positive (\%) & Anaemic (\%) & GMPD \pm SD & GMED \pm SD \\
\hline Malaria & $269(60.72)$ & $7(2.60)$ & $262.83 \pm 2450.24$ & - \\
\hline Malaria/STHs & $120(27.09)$ & $8(6.67)$ & $270.30 \pm 1387.53$ & $447.58 \pm 3182.71$ \\
\hline STHs & $7(1.58)$ & $0(0.00)$ & - & $196.95 \pm 2686.52$ \\
\hline $\begin{array}{l}\text { Level of sig- } \\
\text { nificance }\end{array}$ & $\begin{array}{c}\mathrm{X}^{2}=261.65 \\
\mathrm{P}<0.001\end{array}$ & $\begin{array}{c}\mathrm{X}^{2}=9.99 \\
\mathrm{P}=0.007\end{array}$ & $\begin{array}{c}\text { Mann-Whitney U } \\
\mathrm{P}=0.734\end{array}$ & $\begin{array}{c}\text { Mann-Whitney U } \\
\mathrm{P}=0.269\end{array}$ \\
\hline
\end{tabular}

Table 4: Relationship between disease status and disease severity.

ciparum co-infection $(7.69 \%, 16 / 208)$ was the highest and there was a significant difference $\left(\mathrm{X}^{2}=13.99, p=0.003\right)$ (Table 3). Both P. malariae and $P$. falciparum/ P. malariae infections occurred in the study population but did not co-infect with any helminth species.

\section{Relationship between disease status and disease severity}

Co-infected participants had the highest prevalence of anemia $(6.67 \%, 8)$ when compared to those who had only malaria or STHs and the difference was significant $\left(\mathrm{X}^{2}=9.99, p=0.007\right)$ (Table 4). Those co-infected had a higher GMPD $(270.30 \pm 1387.53)$ than those infected with malaria alone $(262.83 \pm 2450.24)$. The GMED was also higher in the co-infected participants $(447.58 \pm 3182.71)$ than in those infected with STH alone (196.95 \pm 2686.52$)$.

\section{Discussion}

The study showed that the overall prevalence of asymptomatic malaria was significantly higher in the rural area than in the urban area. This is in agreement with a previous report in the region which observed a significant decrease in the prevalence of malaria with an increase in urbanization [1]. Similarly this finding is comparable to ear- lier reports which found asymptomatic malaria parasite rates of over $60 \%$ in southwest Cameroon [5,14]. Southwest Cameroon is known to be a holoendemic area for malaria. Studies elsewhere have reported that the burden of most asymptomatic infections do occur in younger children [2]. The higher prevalence of malaria in the rural area could be linked to a greater risk of vector contact and infection, as a result of stagnant water and thick bushes around houses, lower level of education, poverty and lack of effective preventive measures against malaria in the area. It is also possible that the housing type might have influenced the high prevalence of malaria in the rural area as majority of the houses there were made up of plank with crevices on the walls.

On the other hand the prevalence of malaria was lower in the urban area, Great Soppo. This is a rapidly urbanizing area located along the slope of Mount Cameroon where much run off during the rainy season easily washes away any water in potholes that could act as larval habitats thus leading to a lower prevalence of malaria. Studies have shown that urbanization leads to a reduction in the prevalence of malaria [1] as children living in urban areas generally have better physical access to health services and better preventive measures such as the use of insecticide-treated nets against malaria [18] when compared to those living in rural areas. Higher human population densities could likely reduce the biting rates in the urban area, owing to the higher ratio of humans to mosquito vectors [19].

The prevalences of STHs and co-infections of malaria and STHs were also significantly higher in the rural than urban area. This could be linked to environmental contamination (as some houses lacked latrines thus encouraging defecation on the soil and some inhabitants drank water from wells). STHs infection rates were reported to be significantly higher in schoolchildren in a rural than an urban area in Nigeria [20]. Another study also reported high rates of STHs and their co-infections with malaria in schoolchildren in Kumba, Cameroon [14]. It has been reported that intestinal parasites remain a major health problem in many developing countries in the tropics where they are prevalent in school-aged children who usually play a lot in the soil [21]. A Similar finding on co-infections of malaria and helminths has been reported in Cameroon [13]. Although both malaria and STHs have distinct modes of transmission patterns a variety of environmental and host factors may influence their epidemiological and geographical patterns of infections and diseases [22]. The higher level of urbanization in Great Soppo is likely to have led to greater awareness and better environmental sanitation thereby reducing the prevalence of STHs and their co-infections with malaria. From physical observation, all houses are built with toilets and no wells are present as water sources. This finding is in agreement with a report in Nigeria [2].

Children in the youngest age group had the highest malaria prevalence $(100 \%)$ and parasite load in the rural area and this trend decreased with increasing age and the difference was highly significant. Age related decrease in malaria prevalence and density is probably related to the acquisition of protective immunity due to repeated infections as children grow older in high transmission areas [23]. Malaria prevalences were similar in all age groups in the urban area and parasite densities did not follow any particular pattern.

The results showed that egg densities of A. lumbricoides and T. trichiura were significantly higher in the rural than urban area. Since rural areas tend to have lower levels of sanitation than the urban regions geohelminth infections are more common. This higher likelihood of becoming infected with gut helminths could explain the predicted effect of $A$. lumbricoides species presence being associated with higher T. trichiura species prevalence (results not shown). Envi- 
Citation: Kimbi HK, Lum E, Wanji S, Mbuh JV, Nyanga JLN, et al. (2012) Co-Infections of Asymptomatic Malaria and Soil-Transmitted Helminths in School Children in Localities with Different Levels of Urbanization in the Mount Cameroon Region. J Bacteriol Parasitol 3:134. doi:10.4172/2155-9597.1000134

ronmental conditions are much the same for A. lumbricoides and $T$. trichiura and not surprisingly they overlap in distribution and are more likely to infect together due to their shared transmission route. In our study $P$. falciparum, A. lumbricoides and T. trichiura as well as their coinfections were more common (in both rural and urban areas) than in reports from Tanzania [10]. Interestingly hookworm infections were less common in our study as compared to the study in Tanzania. These differences could be due to geographical variations in exposure and endemicity. Multiple infections of P. falciparum, A. lumbricoides and T. trichiura and hookworms were recorded in our study just as in studies from other countries like Zimbabwe [24] and Tanzania [10] indicating that parasitic infections do not occur singly but as co-infections [12].

In the rural area, anemia prevalence decreased from $2.1 \%$ in children of the youngest age group to $1.3 \%$ in those of age group 8-9 years. A negative interaction between malaria and age on anemia has been documented, whereby the effect of malaria parasitaemia on anemia decreases with age [12]. However, anemia increased to $2.6 \%$ in children aged 10-14 years. This could be due to co-infections of $P$. falciparum/ hookworm since the majority of the hookworm-infected participants were in that age group in the rural area. Studies suggest that co-infections of $P$. falciparum with hookworms tend to exacerbate hepatosplenic anemia and malnutrition morbidities among school children [6].

This study showed that a higher proportion of children who were co-infected with malaria and STHs had more anemia and lower haematocrits than those infected with malaria or STHs alone and the difference was significant. This finding is similar to reports from elsewhere in which co-infected participants had significantly higher levels of anemia when compared to participants infected with only malaria $[8,25]$. Children co-infected with malaria and STHs also had higher GMPD and GMED than those infected with either malaria or STH alone suggesting that helminth infections may exacerbate clinical malaria. Generally, these data suggest an additive impact of STH and malaria co-infection on aggravating anemia, GMPD and GMED in schoolchildren. Other studies speculated that infections with helminths may increase the susceptibility to clinical malaria $[4,26]$. The increased prevalence of anemia in co-infected participants could be attributed to chronic loss of blood and iron as a result of worm infection in addition to the loss due to malaria [25]. Malaria causes anemia through haemolysis and increased spleenic clearance of infected and uninfected red blood cells and cytokine-induced dyserythropoesis [27]. STHs also cause anemia through blood loss, nutritional theft and loss of appetite due to immunological factor [6]. Therefore children with multiple parasitic infections especially those with heavy infection intensity tend to experience more cognitive outcomes and other health problems such as malnutrition than those with single infections [28].

In this study, factors such as the ownership and use of insecticide treated bed nets, house type and socio-economic status of participants which could influence the prevalence of the co-infections were not investigated. There were small sample sizes for different helminth species especially for hookworm and this made it difficult to determine relationships between species. We therefore suggest that these aspects be studied in future on a larger scale in order to throw more light on the factors influencing the prevalences and intensities of the infections and their morbidities in the different localities with varying levels of urbanization.

In conclusion, this study has established that both malaria and STHs co-infect schoolchildren in both rural and urban areas of the Mount Cameroon region and the prevalences of both infections as well as co-infections are higher in the rural than urban area. Considering the public health relevance of these co-infections, it is therefore important to institute some school-based control measures such as intermittent preventive treatment of malaria and STHs and free distribution of insecticide treated bed nets. These interventions will likely reduce malaria and STH related morbidities especially anemia in school-aged children in the area.

\section{Acknowledgements}

We are grateful to all the parents/guardians for their consent and the children who participated in this study. Kakwa Biofarm, Limbe, Cameroon supplied the drugs. This study was supported by a development grant from the University of Buea, Cameroon.

\section{References}

1. Kimbi HK, Nformi D, Patchong AM, Ndamukong KJ (2006). Influence of urbanization on asymptomatic malaria in school children in Molyko, South West Cameroon. East Afr Med J 83: 602-609.

2. Olurongbe O, Adegbayi AM, Bolaji OS, Akindele AA, Adefioye OA, et al. (2011) Asymptomatic falciparum malaria and helmith co-infection among school children in Osogbo, Nigeria. J Res Med Sci 16: 680-686.

3. Montresor A, Crompton DWT, Hall A, Bundy DAP (1998) Guidelines for the evaluation of soil-transmitted helminthiasis and schistosomiasis at community level. World Health Organization, Geneva.

4. Nacher M (2004) Interactions between worm infections and malaria. Clin Rev Allergy Immunol 26: 85-92.

5. Kimbi HK, Awah NW, Ndamukong KJ, Mbuh JV (2005) Malaria infection and its consequences in School children. East Afr Med J 82: 92-97.

6. Hotez JP, Brooker S, Bethony JM, Bottazzi ME, Loukas A, et al. (2004) Hookworm Infection. Infect Eng J Med 351: 799-807.

7. Finkelstein JL, Schleinitz MD, Carabin H, McGarvey ST (2008) Decision mode estimation of the age-specific disability weight for Schistosoma japonica: a systemic review of the literature. Plos Negl Trop Dis 2: e158

8. Nacher M, Singhasivanon P, Silachamroon U, Treeprasertsuk S, Krudsood $S$, et al. (2001) Association of helminth infections with increased gametocyte carriage during mild falciparum malaria in Thailand. Am J Trop Med Hyg 65: 644-647.

9. Spiegel A, Tall A, Raphenon G, Trape JF, Druilhe P (2003) Increased frequency of malaria attacks in subjects co-infected by intestinal worms and falciparum malaria. Trans R Soc Trop Med Hyg 97: 198-199.

10. Mazigo HD, Waihenya R, Lwambo NJ, Mnyone LL, Mahande AM, et al. (2010) Co-infections with Plasmodium falciparum, Schistosoma mansoni and intestinal helminthes among schoolchildren in endemic areas of northwestern Tanzania. Parasit Vectors 3: 44

11. Ndamukong KJ, Ayuk MA, Dinga JS, Akenji TN, Ndiforchu VA, et al. (2000) The pattern of soil-transmitted nematode infections in primary school children of Kumba Health district, South-West Cameroon. Afr J Health Sci 7:103-106.

12. Brooker S, Clements AC, Hotez PJ, Hay SI, Tatem AJ, et al. (2006) The codistribution of Plasmodium falciparum and hookworm among African Schoolchildren. Malar J 5: 99

13. Nkuo-Akenji TK, Chi PC, Cho JF, Ndamukong KK, Sumbele I (2006) Malaria and helminth co-infection in children living in a malaria endemic setting of Mount Cameroon and predictors of anemia. J Parasitol 92: 1191-1195.

14. Adio MB, Ndamukong KJ, Kimbi HK, Mbuh JV (2004) Malaria and intestinal helminthiasis in school children of Kumba Urban area, Cameroon. East Afr Med J 81: $583-588$

15. Achidi EA, Apinjoh TO, Mbunwe E, Besingi R, Yafi C, et al. (2008) Febrile status, malarial parasitaemia and gastro-intestinal helminthiases in schoolchildren resident at different altitudes in south-western Cameroon. Ann Trop Med Parasitol 102: 103-118

16. Cheesbrough M (2005) Parasitological tests in district laboratory practice in tropical countries. Cambridge Low-Price Editions, Cambridge University Press, Cambridge.

17. Katz N, Chavez A, Pellegrino J (1972) A simple device for quantitative stoo 
Citation: Kimbi HK, Lum E, Wanji S, Mbuh JV, Nyanga JLN, et al. (2012) Co-Infections of Asymptomatic Malaria and Soil-Transmitted Helminths in School Children in Localities with Different Levels of Urbanization in the Mount Cameroon Region. J Bacteriol Parasitol 3:134. doi:10.4172/2155-9597.1000134

Page 6 of 6

thick smear technique in Schistosoma mansoni. Rev Inst Med Trop Sao Paulo 14: $397-400$.

18. Holtz TH, Marum LH, Mkandala C, Chizani N, Roberts JM, et al. (2002) Insecticide-treated bednet use, anaemia, and malaria parasitaemia in Blantyre District, Malawi. Trop Med Int Health 7: 220- 230.

19. Robert V, Macintyre K, Keating J, Trape JF, Duchemin JB, et al. (2003) Malaria transmission in urban sub-Saharan Africa. Am J Trop Med Hyg 68:169-176.

20. Oninla SO, Owa JA, Onayade AA, Taiwo O (2007) Intestinal helminthiases among rural and urban schoolchildren in south-western Nigeria. Ann Trop Med Parasitol 101: 705-713.

21. Utzinger J, Vounatsou P, N'Goran EK, Tanner M, Booth M (2002) Reduction in the prevalence and intensity of hookworm infectioms after praziquantel treatment for schistosomiasis infection. Int J Parasitol 32: 759-765.

22. Mwangi TW, Bethony JM, Brooker S (2007) Malaria and helminthes interactions in humans: an epidemiological viewpoint. Ann Trop Med Parasitol 100: 551-570.

23. Quakyi IA, Leke RG, Befidi-Mengue R, Tsafack M, Bomba-Nkolo D, et al.
(2000) The epidemiology of Plasmodium falciparum malaria in two Cameroonian villages: Simbok and Etoa. Am J Trop Med Hyg, 63: 222-230.

24. Midzi N, Sangweme D, Zinyowera S, Mapingure MP, Brouwer KC, et al. (2008) The burden of Polyparasitism among primary schoolchildren in rural and farming areas in Zimbabwe. Trans R Soc Trop Med Hyg 102: 1039-1045.

25. Degarege A, Animut A, Legesse M, Erko B (2010) Malaria and helmith co-infections in outpatients of Alaba Kulito Health Center, southern Ethiopia: a cross sectional study. BMC Res Notes 3: 143.

26. Druilhe P, Tall A, Sokhna C (2005) Worms can worsen malaria: toward a new means to roll back malaria? Trends Parasitol 21: 359-362.

27. Crawley J (2004) Reducing the burden of anaemia in infants and young children in malaria-endemic countries of Africa: from evidences to action. Am J Trop Med Hyg 71: 25-34.

28. Jardim-Botelho A, Raff S, Rodrigues Rde A, Hoffman HJ, Diemert DJ, et al (2008) Hookworm, Ascaris lumbricoides infections and polyparasitism associated with poor cognitive performance in Brazilian schoolchildren. Trop Med Int Health 13: 994-1004. 